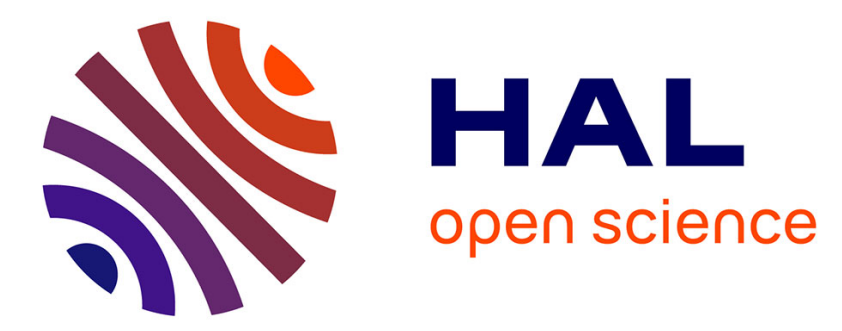

\title{
Effect of Aging on Phosphorus Speciation in Surface Deposit of a Vertical Flow Constructed Wetland
}

Boram Kim, Mathieu Gautier, Camille Rivard, Corinne Sanglar, Philippe Michel, Rémy Gourdon

\section{To cite this version:}

Boram Kim, Mathieu Gautier, Camille Rivard, Corinne Sanglar, Philippe Michel, et al.. Effect of Aging on Phosphorus Speciation in Surface Deposit of a Vertical Flow Constructed Wetland. Environmental Science and Technology, 2015, 49 (8), pp.4903-4910. 10.1021/es506164v . hal-01302471

\section{HAL Id: hal-01302471 \\ https://hal.science/hal-01302471}

Submitted on 14 Apr 2016

HAL is a multi-disciplinary open access archive for the deposit and dissemination of scientific research documents, whether they are published or not. The documents may come from teaching and research institutions in France or abroad, or from public or private research centers.
L'archive ouverte pluridisciplinaire HAL, est destinée au dépôt et à la diffusion de documents scientifiques de niveau recherche, publiés ou non, émanant des établissements d'enseignement et de recherche français ou étrangers, des laboratoires publics ou privés. 


\title{
Effect of aging on phosphorus speciation in surface deposit of a vertical flow constructed wetland
}

\author{
Boram Kim*, Mathieu Gautier", Camille Rivard, \\ Corinne Sanglar, Philippe Michel, and Rémy Gourdon
}

$\rightarrow$ To cite this version:

Boram Kim, Mathieu Gautier, Camille Rivard, Corinne Sanglar, Philippe Michel, and Rémy Gourdon. Effect of aging on phosphorus speciation in surface deposit of a vertical flow constructed wetland. Environ. Sci. Technol., 2015, 49(8), pp 4903-4910.

Please contact the corresponding authors (*) if you are interested by a copy of the article published in the journal. 


\title{
Effect of aging on phosphorus speciation in surface
}

\section{deposit of a vertical flow constructed wetland}

\author{
Boram Kim,,${ }^{*} \dagger$, Mathieu Gautier, ${ }^{*} \dagger$ Camille Rivard, ${ }^{\S}$ Corinne Sanglar, ${ }^{,}$Philippe Michel, ${ }^{\ddagger}$ and Rémy \\ Gourdon $^{\dagger}$
}

${ }^{\dagger}$ INSA Lyon, University of Lyon, LGCIE - DEEP, 20 av. A. Einstein, 69621 Villeurbanne cedex, France

‡SCIRPE, 5 Allée Alban Vistel, 69110 Sainte-Foy-Lès-Lyon, France

${ }^{\S}$ ESRF, European Synchrotron Radiation Facility, 38000 Grenoble, France

' ISA, Institut des Sciences Analytiques, 5 rue de la Doua, 69100 Villeurbanne, France AUTHOR INFORMATION

\section{Corresponding Authors}

* E-mail: mathieu.gautier@insa-lyon.fr; Phone: +33(0)4 72438348

* E-mail: boram.kim@cpe.fr; Phone: +33(0)4 72208780 


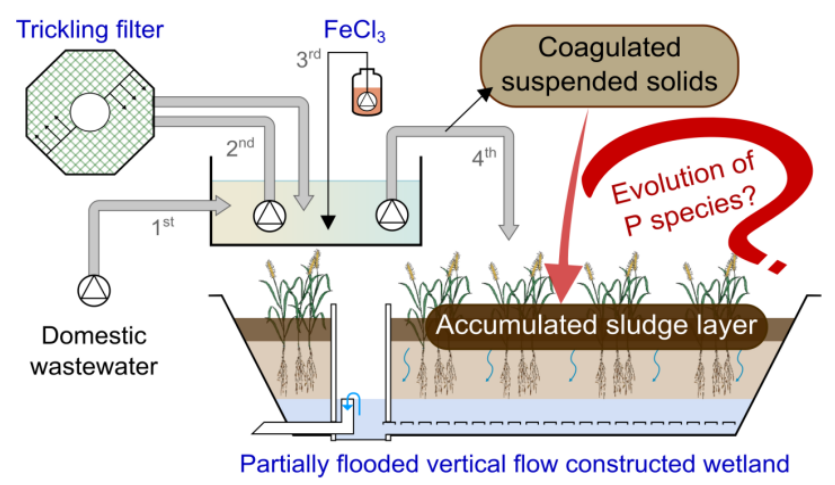

This study was conducted to determine phosphorus (P) species captured in a vertical-flow constructed wetland (VFCW) system combining a trickling filter followed by $\mathrm{FeCl}_{3}$ injection for phosphate coagulation. Suspended solids (SS) thus formed accumulated over time at the VFCW surface and transformed into a sludge deposit layer, which was shown to concentrate most of the $\mathrm{P}$ captured in the system. In order to investigate the effect of aging on P species, representative SS and sludge samples were taken from a wastewater treatment plant that had been in operation for 8 years and analyzed using $\mathrm{P}$ fractionation, solution ${ }^{31} \mathrm{P}$ NMR spectroscopy and $\mathrm{P}$ and Fe K-edge XANES spectroscopy. A partial mineralization of organic matter was shown by comparing organic carbon contents of SS and sludge materials. Chemical fractionations combined with P and Fe K-edge XANES spectroscopy showed that $\mathrm{P}$ was predominantly bound to iron within both samples in the form of ferric phosphate, rather than adsorbed onto ferric oxyhydroxide. Calcium-bound $\mathrm{P}$ was more significantly observed in sludge than in SS, suggesting that aging induced the recombination of part of the organic and iron-bound $\mathrm{P}$ species into calcium-bound forms, as a possible consequence of the partial mineralization of organic matter.

\section{KEYWORDS}

Vertical flow constructed wetland; Sludge; Phosphorus Fractionation; Solution ${ }^{31} \mathrm{P}$ NMR; Phosphorus K-edge XANES; Ferric chloride; Mineralization; Aging; Speciation 


\section{INTRODUCTION}

Phosphorus $(\mathrm{P})$ is an element which may be considered under two points of view. In the agricultural sector, $\mathrm{P}$ is seen as a beneficial fertilizing element needed to optimize crops yields, whereas it is perceived as a pollutant in the environmental protection field ${ }^{1-3}$ since its release into surface aquatic ecosystems may induce eutrophication. Phosphorus treatment from domestic wastewaters has therefore received increasing attention in recent years.

A particular combined wetland treatment process (AZOE-NP, EP1857419A1; WO2012150296) has been developed for the treatment of domestic wastewaters from small communities ${ }^{4,5}$. In this process, $\mathrm{P}$ removal is done by ferric chloride $\left(\mathrm{FeCl}_{3}\right)$ injection at the outflow of a trickling filter used as a biological pretreatment, in order to transform dissolved reactive $\mathrm{P}$ into particulate forms mixed with organic matter from the wastewater. The suspended solids (SS) thus formed are then separated from the effluent by filtration through two successive stages of partially flooded vertical-flow constructed wetland (VFCW). The suspended solids progressively accumulate at a rate of about $2 \mathrm{~cm} / \mathrm{year}$ at the surface of VFCWs, where they form a sludge deposit layer, which is planned to be removed by dredging every 10 to 15 years. Molle ${ }^{6}$ highlighted the necessity to better understand the phenomena occurring in deposit layer of these VFCW systems, which is considered as a key component in the treatment processes.

Kim et al. ${ }^{7}$ recently reported a chemical and mineralogical characterization of these materials and showed that the surface sludge layer constituted an important stock of $\mathrm{P}$ (above $2 \% \mathrm{w} / \mathrm{w}$ of $\mathrm{P}$ in dry matter). The surface deposit layer may therefore be considered both as a potential source of $\mathrm{P}$ release to receiving environment during wastewater treatment operation and as a potential organic soil fertilizer after dredging. Qualitative and quantitative descriptions of $\mathrm{P}$ species are still needed to better estimate the mobility or availability of $\mathrm{P}$ in the material ${ }^{8}$.

The determination of $\mathrm{P}$ speciation in complex environmental samples requires complementary techniques and protocols. Sequential extractions (fractionation method) provide quantitative information on the $\mathrm{P}$ pools within different fractions ${ }^{9-13}$. However, the method cannot identify the chemical forms of $\mathrm{P}$ compounds and other techniques are therefore needed ${ }^{14}$. Solution ${ }^{31} \mathrm{P}$ NMR spectroscopy is used to investigate molecular speciation of organic P species such as orthophosphates monoesters, diesters, and phosphonates ${ }^{2,15,16}$. In addition, X-ray absorption near edge structure (XANES) spectroscopy and X-ray fluorescence (XRF) mapping at P K-edge appears as a powerful analytical method to identify inorganic $\mathrm{P}$ forms within solid samples ${ }^{8,17,18}$. 
The above-mentioned analytical techniques were used in the present study to provide complementary information on the nature and relative proportions of $\mathrm{P}$ species within organic materials sampled from a vertical-flow constructed wetland (VFCW) plant. The objective was to characterize $\mathrm{P}$ forms in the sludge deposit collected from a constructed wetland and evaluate the effect of aging by comparing to the SS from which the sludge deposit was formed.

\section{MATERIALS AND METHODS}

\section{Sampling and preparation of samples}

Samples were collected in April 2012 from a municipal vertical-flow constructed wetland located in Vercia (Jura, France). This unit, in operation since 2004, is the first AZOE-NP full-scale plant. It treats mostly domestic wastewater, but also receives winery effluent in autumn. Its maximum capacity corresponds to 1100 people equivalent (PE). The contribution of winery effluent was estimated below $1 \%$ and $6 \%$ of the total annual hydraulic and organic loads received by this plant, respectively. The average depth of surface sludge layer accumulated on the first stage of this plant since its operation was around $16 \mathrm{~cm}$, corresponding to a rate of accumulation of about $2 \mathrm{~cm}$ per year.

Two types of materials were taken from the plant. Suspended solids (SS) were sampled by sieving at $45 \mu \mathrm{m}$ the outlet effluent of the trickling filter after $\mathrm{FeCl}_{3}$ injection followed by filtration with acetate cellulose filter at $0.45 \mu \mathrm{m}$. Sludge material was sampled from the surface layer of the first VFCW stage. Primary sampling of the sludge was conducted using a power shovel to extract the entire depth of the deposit layer from different spots of the first filter surface. The samples were then treated manually to sort out rhizomes and coarse fractions (gravels), and subsequently mixed by quartering before being transported to the laboratory. There, an aliquot fraction was stored at $4{ }^{\circ} \mathrm{C}$ for a maximum of 2 days until it was freeze-dried and finely ground for subsequent analyses. Elemental analysis was first performed by alkaline fusion $\left(\mathrm{LiBO}_{2}\right)$ followed by acid digestion and subsequent analyses of the solutions using inductively coupled plasma atomic emission spectrometry (ICP-AES).

\section{Sequential $P$ fractionation}

The protocol proposed by Golterman ${ }^{12}$ was followed. This method involves chelating reagents which are meant to extract selectively the different types of $\mathrm{P}$ species present in the sample (especially iron- 
bound $\mathrm{P}$ species). Two aliquots of each sample were extracted with a solid to solution ratio of $1 \mathrm{~g}: 100 \mathrm{~mL}$ according to the following steps:

- 1 extraction for $2 \mathrm{~h}$ with deionized water;

- 4 extractions for $2 \mathrm{~h}$ with $0.05 \mathrm{M} \mathrm{Ca}-\mathrm{EDTA}+1 \%$ of Na-dithionite ( $\mathrm{pH}$ around 7.5);

- 2 extractions for $16 \mathrm{~h}$ with $0.1 \mathrm{M} \mathrm{Na}-\mathrm{EDTA}(\mathrm{pH} \mathrm{4.5)}$;

- 1 extraction for 30 min with $0.25 \mathrm{M} \mathrm{H}_{2} \mathrm{SO}_{4}$;

- 1 extraction for 30 min with $1 \mathrm{M} \mathrm{NaOH}$ at $90{ }^{\circ} \mathrm{C}$;

- persulphate digestion of residual P.

Extracted P at each step was respectively considered as associated with the following compartments: water-soluble phosphate $\left(\mathrm{H}_{2} \mathrm{O} \sim \mathrm{P}\right)$, iron bound phosphate $(\mathrm{Fe} \sim \mathrm{P})$, calcium bound phosphate $(\mathrm{Ca} \sim \mathrm{P})$, acid soluble organic phosphate (ASOP, $\left.\mathrm{P}_{\text {org-acid }}\right)$, alkali soluble organic phosphate $\left(\mathrm{P}_{\text {org-alk }}\right)$, and residual $\mathrm{P}\left(\mathrm{P}_{\text {res }}\right)$. All extractions were carried out under continuous rotary shaking. Following extraction, each suspension was centrifuged (4000 rpm; $3400 \mathrm{~g}$ ) for $15 \mathrm{~min}$, then an aliquot fraction of the supernatant was analyzed for determination of dissolved molybdate reactive P (MRP; mainly composed of orthophosphates) and of total P. The MRP was measured by the molybdate-blue method ${ }^{19}$. Absorbance was read after $40 \mathrm{~min}$, in agreement with the time scale for the formation of phosphate molybdate complex. All analyses were duplicated. Total P was measured by ICP-AES (Ultima 2; Horiba Jobin Yvon SAS). The difference between total $\mathrm{P}$ and MRP was referred as molybdate unreactive P (MUP) which was considered to include complex inorganic P forms, non-hydrolyzed organic $\mathrm{P}$ and colloidal $\mathrm{P}^{2,20}$.

\section{Solution ${ }^{31} \mathrm{P}$ nuclear magnetic resonance spectroscopy}

\section{Phosphorus extraction}

Phosphorus was first extracted by mixing for $16 \mathrm{~h}$ at room temperature freeze-dried samples in a $0.25 \mathrm{M} \mathrm{NaOH}+50 \mathrm{mM} \mathrm{Na} 2$ EDTA aqueous solution with a solid/liquid ratio of $1 \mathrm{~g} / 20 \mathrm{~mL}$. The suspension was then centrifuged at $3400 \mathrm{~g}$ for $15 \mathrm{~min}$, and the supernatants filtered with $0.45 \mu \mathrm{m}$ through Sartorius Minisart filters (poly(ether sulfone) membrane). Each extract was divided into two aliquots. The first aliquot was used for the analysis of total extracted P concentration by ICP-AES (Ultima 2; Horiba Jobin Yvon SAS) and the second aliquot was freeze-dried and subsequently homogenized by manual grinding into a fine powder for NMR analysis. 


\section{Sample preparation and NMR spectra acquisition}

Solution ${ }^{31} \mathrm{P}$ NMR spectra were recorded at $30^{\circ} \mathrm{C}$ on a Bruker Avance III HD $400 \mathrm{MHz}$ spectrometer equipped with a $5 \mathrm{~mm}$ QNP (Quattro Nucleus Probe) probe with z-gradients and operated at 161.972 MHz. Each sample was prepared as follows: $100 \mathrm{mg}$ of extract were dissolved into $900 \mu \mathrm{L}$ of $\mathrm{NaOH} / \mathrm{EDTA}$ solution and $100 \mu \mathrm{L}$ of $\mathrm{D}_{2} \mathrm{O}$. Phosphorus-31 spectra were recorded using $4.33 \mu$ s pulse $\left(60^{\circ}\right)$, a delay time of $2 \mathrm{~s}$, an acquisition time of $0.255 \mathrm{~s}$ and a number of scans of 4096 . Data were processed using the $5 \mathrm{~Hz}$ line broadening. Data interpretations were done using Bruker NMR Software Topspin (3.2). Chemical shifts were indirectly referenced to $\mathrm{H}_{3} \mathrm{PO}_{4}$ solution (at $\delta=0 \mathrm{ppm}$ ).

\section{XANES spectroscopy and XRF mapping at $P$ and Fe K-edge}

\section{Origins of reference compounds}

Mineral and organic P compounds were analyzed and used as references for the interpretation of XANES spectra collected on the samples. The standard compounds were selected based on hypotheses on the possible forms of $\mathrm{P}$ in the considered samples which were issued on the one hand from the probable mechanisms of $\mathrm{P}$ reaction with ferric ions, and on the other hand from the results of $\mathrm{P}$ fractionation and ${ }^{31} \mathrm{P}$ NMR. Two major mechanisms are reported for the reaction between phosphates and ferric ions in aqueous solutions, namely precipitation of ferric phosphate species and / or phosphates adsorption onto hydrous ferric oxides (HFO), notably ferryhydrite ${ }^{21,22}$. For P K-edge analyses, the following analytical-grade compounds were therefore selected: adenosine triphosphate (ATP), inositol phosphate, and dihydrated iron (III) phosphate $\left(\mathrm{FePO}_{4} 2 \mathrm{H}_{2} \mathrm{O}\right)$ were purchased from Sigma-Aldrich. Sedimentary apatite from Morocco was provided and described by Harouiya et al. ${ }^{23}$. Amorphous calcium phosphate (ACP) and phosphates adsorbed onto ferrihydrite (FeOOH) were purposely synthesized by the authors. ACP was synthesized at $30{ }^{\circ} \mathrm{C}$ using the method described by Eveborn et al. ${ }^{8}$. Phosphates adsorbed onto FeOOH were prepared as described by Golterman ${ }^{24}$. At Fe K-edge, only $\mathrm{FePO}_{4}$ and phosphates adsorbed on ferrihydrite were analyzed, as they were considered as the predominant possible forms based on other authors' previous work ${ }^{22}$ and on the physical-chemical conditions of ferric chloride injection (final $\mathrm{pH}$ around 7 and mean $\mathrm{Fe} / \mathrm{P}$ ratio of 2.8). 


\section{References and samples preparation}

For XANES analyses, all reference compounds and samples (SS and sludge) were manually finely ground unless otherwise specified. When possible, the XANES spectra were recorded in transmission mode. When P concentration was too low, the XANES spectra were recorded in fluorescence mode. Table 1 summarizes the conditions used for the different samples. The samples analyzed in transmission were spread into a thin and uniform layer onto a $\mathrm{P}$ and Fe-free adhesive tape. The samples analyzed in fluorescence were pressed to obtain $3 \mathrm{~mm}$ diameter pellets. At Fe K-edge, due to the high Fe concentration, the sludge sample powder was diluted 50 times in boron nitride before pellet preparation to avoid self-absorption. For micro-XRF ( $\mu$-XRF) mapping and micro-XANES ( $\mu$ XANES) analyses at $\mathrm{P}$ and Fe K-edge, SS, and sludge were dropped, without fine grinding onto a $\mathrm{P}$ and Fe-free adhesive tape. Pellets and pieces of adhesive tape were then placed in the holes of the sample holders and sealed between two ultralene foils.

\section{Table 1. Standards and samples preparation and acquisition mode for XANES.}

\begin{tabular}{|c|c|c|c|}
\hline Standards & Preparation & Edge & Acquisition mode \\
\hline $\begin{array}{l}\mathrm{FePO}_{4}, \mathrm{ACP} \text {, apatite, } \\
\text { inositol phosphate, ATP }\end{array}$ & Thin film on adhesive tape & $\mathrm{P}$ & transmission \\
\hline $\begin{array}{l}\mathrm{PO}_{4}{ }^{3-} \text { adsorbed on } \\
\text { ferrihydrite }\end{array}$ & Pure pellets & $\mathrm{P}$ & fluorescence \\
\hline $\begin{array}{l}\mathrm{FePO}_{4}, \mathrm{PO}_{4}{ }^{3-} \text { adsorbed on } \\
\text { ferrihydrite }\end{array}$ & Thin film on adhesive tape & $\mathrm{Fe}$ & transmission \\
\hline \multicolumn{4}{|l|}{ Samples } \\
\hline SS, sludge & $\begin{array}{l}\text { Pure pellets and powder on } \\
\text { adhesive tape (micro-analyses) }\end{array}$ & $\mathrm{P}$ & fluorescence \\
\hline sludge & $\begin{array}{l}50 \text { times diluted pellet and } \\
\text { powder on adhesive tape } \\
\text { (micro-analyses) }\end{array}$ & $\mathrm{Fe}$ & $\begin{array}{l}\text { fluorescence, } \\
\text { transmission }\end{array}$ \\
\hline
\end{tabular}

\section{XANES and $\mu-X R F$ maps acquisitions}

Micro-XRF $(\mu-\mathrm{XRF})$ maps and XANES spectra were collected at the European Synchrotron Radiation Facility (ESRF, Grenoble, France) at the ID21 X-ray microscopy beamline ${ }^{25}$. The beam was monochromatized by use of a fixed-exit double crystal $\mathrm{Si}(111)$ or $\mathrm{Si}(220)$ monochromator for $\mathrm{P}$ or $\mathrm{Fe}$ 
K-edge analyses, respectively. The monochromator energy was calibrated using the position of the white line of the spectrum of tricalcium phosphate $\left(\mathrm{Ca}_{3}\left(\mathrm{PO}_{4}\right)_{2}\right)$ at $2152.7 \mathrm{eV}$ and the position of the first derivative of the spectrum of a Fe foil at $7111.0 \mathrm{eV}$. The beam size was reduced using a $200 \mu \mathrm{m}$ pinhole for XANES standards and bulk samples acquisition in unfocused mode and the beam was focused to $0.7 \times 0.3(\mathrm{~h}) \times(\mathrm{v}) \mu \mathrm{m}^{2}$ by means of a Kirkpatrick-Baez mirror arrangement for $\mu-\mathrm{XRF}$ and $\mu$-XANES analyses.

Phosphorus K-edge XANES spectra were collected from 2130 to $2200 \mathrm{eV}$ with a $0.2 \mathrm{eV}$ energy step and Fe K-edge spectra were collected from 7050 to $7350 \mathrm{eV}$ with a $0.3 \mathrm{eV}$ energy step. Quick scan of $0.1 \mathrm{~s}$ were recorded in continuous scan mode and summed (2 to 30 spectra on each spot, depending upon $\mathrm{P}$ or Fe concentration and matrix). For XANES analyses on samples prepared as pellet, three areas were investigated on the pellet to check for the homogeneity of the preparation. XRF maps were acquired above $\mathrm{P}$ and Fe K-edge (2.25 and $7.35 \mathrm{keV}$, respectively) with 1 to $5 \mu \mathrm{m}$ step. Points of interest (POIs) were selected from these maps, mainly on P-rich areas for P K-edge XANES and based on the P-Fe correlation maps for Fe K-edge XANES.

Phosphorus and Fe K-edge XANES spectra were reduced using standard normalization procedure described in Athena package ${ }^{26,27}$. Edge energy $\left(\mathrm{E}_{0}\right)$ was chosen as the maximum of the first derivative. Spectra were normalized relatively to the absorption above the threshold. The contributions of the different standards to the sludge Fe K-edge XANES spectrum were determined using the linear combination fitting (LCF) function proposed in Athena. The fit range was from -25 to $+100 \mathrm{eV}$ around $\mathrm{E}_{0}$. All standards weights were forced to be between 0 and 1 and sum was forced to 1 . No $\mathrm{E}_{0}$ shift was allowed for the standard.

\section{RESULTS AND DISCUSSIONS}

\section{Chemical composition and $P$ fractionation}

Chemical compositions of SS and sludge samples are presented in Table 2. The decrease in organic content between SS and sludge revealed the partial biodegradation of organic matter as discussed in a previously published article ${ }^{7}$. Total $\mathrm{P}$ content was found to be 1.4 and $2.6 \% \mathrm{w} / \mathrm{w}$ in SS and sludge, respectively. The fact that $\mathrm{P}$ concentration was much higher in the sludge than in the SS, even though no possible process could have induced a production of $\mathrm{P}$ within the sludge, was an indication that other constituents of the solid material were degraded and extracted out of the particles, whereas $\mathrm{P}$ 
remained in the solid. The biodegradation and probably mineralization of the organic matter was considered as the major process to explain the observation.

Table 2. Chemical composition of suspended solids (SS) and sludge materials (all data are expressed as $\% \mathrm{w} / \mathrm{w}$ with respect to dry matter)

\begin{tabular}{lrr} 
& SS $^{*}$ & Sludge \\
$\mathrm{Si}$ & 1.1 & 8.9 \\
$\mathrm{Al}$ & 0.3 & 3.1 \\
$\mathrm{Fe}$ & 1.7 & 3.8 \\
$\mathrm{Mg}$ & 0.01 & 0.03 \\
$\mathrm{Ca}$ & 3.3 & 4.5 \\
$\mathrm{Na}$ & 1.6 & 0.1 \\
$\mathrm{~K}$ & 0.5 & 0.6 \\
$\mathrm{Ti}$ & 0.04 & 0.2 \\
$\mathrm{P}$ & 1.4 & 2.6 \\
$\mathrm{LOI}$ & 84.9 & 55.8 \\
$\mathrm{C}$ & 35.8 & 26 \\
$\mathrm{~N}$ & 5.08 & 3.03 \\
$\mathrm{~S}$ & 0.31 & 0.67 \\
& & \\
\hline & &
\end{tabular}

${ }^{\dagger}$ Loss on ignition at $1000^{\circ} \mathrm{C}$

The results of $\mathrm{P}$ fractionation analyses are given in Figure 1. Water extractable fraction was about $9.4 \%$ of total $\mathrm{P}$ in SS. This relatively labile fraction was mainly composed of colloidal organic $\mathrm{P}$ species (MUP) rather than inorganic orthophosphates (MRP). It can be seen that $\mathrm{P}$ was predominantly bound to iron in the suspended solids since Fe-P species accounted for $82.4 \%$ of total P. The significant 
proportion of MUP in Fe-P fraction (17.2\%) indicated that $\mathrm{FeCl}_{3}$ reacted not only with dissolved orthophosphate, but also with organic compounds containing P. A fairly high proportion of alkali soluble organic $\mathrm{P}$ was also observed $\left(\mathrm{P}_{\text {org-alk }} ; 7.9 \%\right.$ of total $\mathrm{P}$ ), whereas $\mathrm{Ca}, \mathrm{Al}-\mathrm{P}$ species and acidsoluble organic $\mathrm{P}$ species were observed in much smaller proportions.

Figure 1. Phosphorus fractionation by sequential extractions of suspended solids (SS) and sludge samples. Results are expressed as mass \% of total $P$ contents; molybdate unreactive phosphorus ( $P_{\text {MUP }}$ ) calculated as the difference between $P_{\text {Tot }}$ (determined by ICP-AES) and molybdate reactive phosphorus $\left(\mathrm{P}_{\mathrm{MRP}}\right)$ for each extract.

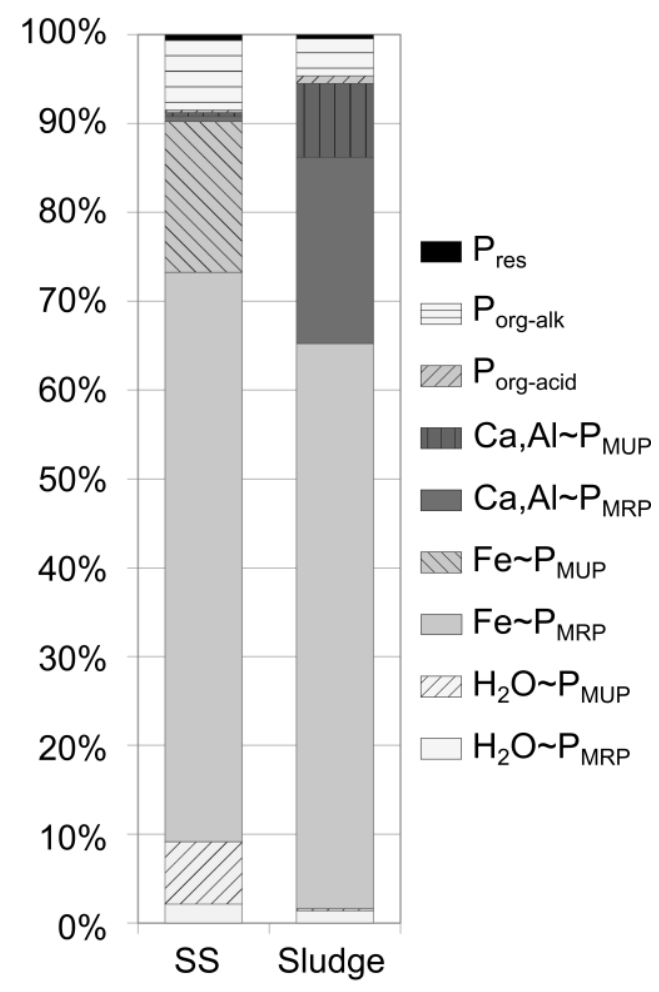

Regarding the sludge, the water extractable fraction was significantly present, but at lower proportions in sludge than SS (1.5\% of total $\mathrm{P})$, indicating the decrease of easily available $\mathrm{P}$ fraction in sludge. The fraction of Fe-P species were also predominant (60.9\% of total P) but to a smaller extent than in the SS. Unlike SS, this fraction in sludge was entirely composed of MRP forms, suggesting that the organic P species (MUP) associated with Fe in SS were transformed into MRP or other P forms over time, probably via the mineralization of organic matter. In addition, Ca,Al-P species were found at 
a much higher proportion in sludge material $(28.0 \%$ of total $\mathrm{P})$ than in SS $(1.0 \%)$, suggesting the formation of calcium phosphates over time. Acid soluble organic P species remained in small proportion within the sludge $(0.8 \%$ of total $\mathrm{P})$, while $\mathrm{P}_{\text {org-alk }}$ fraction $(4.0 \%$ of total $\mathrm{P})$ was less in sludge as compared to SS. This non-proportional evolution of $\mathrm{P}_{\text {org-acid }}$ versus $\mathrm{P}_{\text {org-alk }}$ fractions indirectly indicated changes in the nature of organic matters during aging.

\section{Organic P speciation by solution ${ }^{31} \mathrm{P}$ NMR spectroscopy}

Solution ${ }^{31} \mathrm{P}$ NMR spectra of NaOH-EDTA extracts are shown in Figure 2 and the concentrations of different $\mathrm{P}$ compound classes determined by ${ }^{31} \mathrm{P}$ NMR in each sample are given in Table 3 . Literature data were used for peak assignments as follows: peaks between 17 and $21 \mathrm{ppm}$ were assigned to phosphonates $^{28}$, peaks between 5.3 and $6.6 \mathrm{ppm}$ to orthophosphate ${ }^{28,29}$, between 3.0 and $5.0 \mathrm{ppm}$ to orthophosphate monoesters $^{29}$, between -1.0 and $2.5 \mathrm{ppm}$ to orthophosphate diesters ${ }^{30}$ and between -4.5 and $-3.5 \mathrm{ppm}$ to pyrophosphate ${ }^{31}$. Polyphosphates, usually found around $-19.0 \mathrm{ppm}^{31}$, were not observed in any spectrum.

For both SS and sludge samples, P was mostly present as orthophosphate in the NaOH-EDTA extracts (78.8\% and $91.9 \%$ of total extracted P, respectively). These proportions of orthophosphates were in the same order of magnitude as determined by $\mathrm{P}$ fractionation (75.9\% and $86.3 \%$, respectively). Table 3 and Figure 2 show that monoesters were the predominant forms of organic P species (43.7\% and $70.4 \%$ of organic $\mathrm{P}$, respectively), followed by diesters species (34.9\% and 9.7\% of organic $\mathrm{P}$, respectively). A higher proportion of pyrophosphate (\% of organic P) was observed in suspended solids as compared to sludge ( $\%$ of organic P). Suspended solids were also found to contain higher proportions of orthophosphate monoesters, diesters, and pyrophosphates than sludge, while phosphonates fraction was slightly smaller in SS than sludge.

The decrease of pyrophosphates contents from SS to sludge could be explained by their enzymatic hydrolysis into orthophosphate during the mineralization process ${ }^{32-35}$. Phosphonates were not detected in SS but observed at about $1.0 \%$ of extracted $\mathrm{P}$ in sludge sample. According to Tate and Newman ${ }^{36}$, phosphonates accumulation can be observed in soils under wet and cold conditions, which reduce microbial activities. Since the analyzed sludge sample was taken from an 8-year old surface deposit layer, it may be expected that phosphonate accumulation could occur during each winter. 
Figure 2. Solution ${ }^{31} \mathrm{P}$ NMR spectra of NaOH-EDTA extracts of suspended solids (SS) and sludge samples.

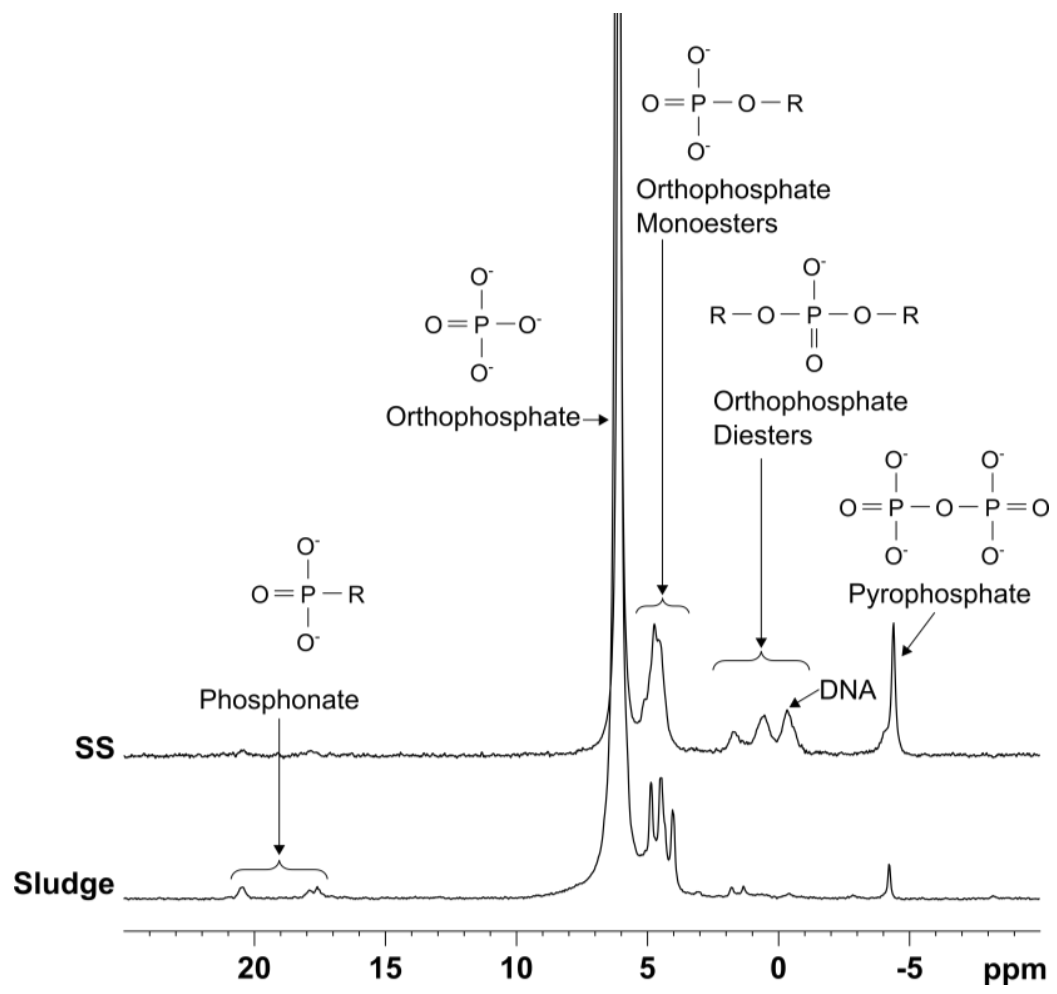

Table 3. Concentrations and relative proportions (\% of total extracted organic P) of different $P$ compound classes determined by ${ }^{31} \mathrm{P}$ NMR.

\begin{tabular}{|c|c|c|c|c|c|c|}
\hline & $\begin{array}{l}\mathrm{P} \text { extraction }(\% \text { of } \\
\text { total dry matters) }\end{array}$ & $P_{\text {Pyro }}(\%)$ & $\begin{array}{c}\text { POrtho-mono } \\
(\%)\end{array}$ & $\mathrm{P}_{\text {Ortho-di }}(\%)$ & $\begin{array}{c}P_{\text {Phosphonate }} \\
(\%)\end{array}$ & $\mathrm{di} /$ mono $^{b}$ \\
\hline SS & 95.9 & 21.4 & 43.7 & 34.9 & $-{ }^{a}$ & 0.80 \\
\hline Sludge & 92.9 & 7.7 & 70.4 & 9.7 & 12.2 & 0.14 \\
\hline
\end{tabular}

A strong decrease of the ratio between orthophosphate diesters and monoesters was observed from SS to sludge, suggesting a stronger degradation of diesters and confirming the qualitative evolution of organic matters as discussed above. This observation seems logical since diesters are generally 
considered as more easily bioavailable than monoesters, which are protected by sorption to soil organic matters, clays or sesquioxides in soil ${ }^{37-39}$.

\section{Speciation of Inorganic P by XRF and XANES}

\section{$X A N E S$ spectra of $P$ - and Fe-references}

Most of the references were analyzed specifically in this study, and their spectra are displayed in Figure 3-a. Additional references spectra are available from the literature $e^{8,17,40-52}$.

Figure 3. (a) Phosphorus (P) K-edge XANES spectra of a selection of reference $P$ minerals (black lines) and organic P species (gray lines). (b) P K-edge XANES spectra of the sludge and SS samples, collected using an unfocused beam (bottom) and on selected points of interest (p1 to p5) using a $\mu$-beam (top).
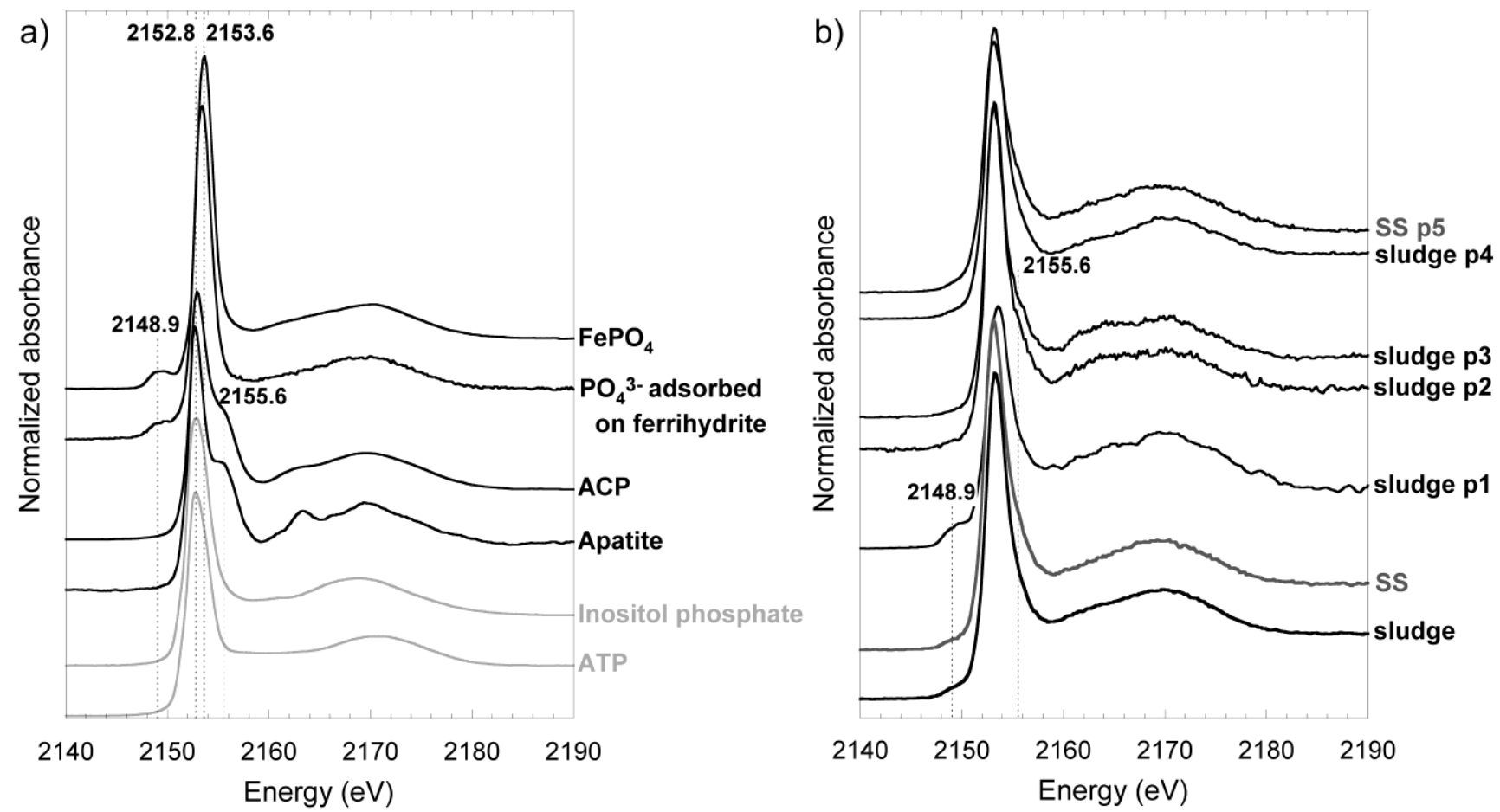

Figure 3 shows that the energy position of the white line of $\mathrm{P}$ K-edge XANES spectra of the reference species did not vary by more than $1 \mathrm{eV}$. Specific features of the XANES spectra (the presence, the shape and position of the pre-edge, the presence and position of shoulder and oscillations 
after the edge) allowed the identification of the species. More specifically, the presence of a postedge shoulder and oscillations at 2163.2 and $2169.4 \mathrm{eV}$, respectively, was taken as characteristic of the apatitic-group minerals and of orthophosphates adsorbed onto calcite ${ }^{17,50,53}$. The amplitude of these features increased with the degree of crystallinity of the mineral as illustrated by the comparison between apatite and ACP (Figure 3-a). It also varied with the number of phosphates groups and the level of hydration ${ }^{8,54}$. The presence of a pre-edge around $2149.5 \mathrm{eV}$, was assigned to the presence of phosphates- $\mathrm{Fe}^{\mathrm{III}}$ bonds ${ }^{55}$. As a result, the $\mathrm{FePO}_{4}$ spectrum was akin to those of phosphates adsorbed on iron oxides and to hydroxides spectra (comparison between $\mathrm{FePO}_{4}$, and phosphates adsorbed onto ferrihydrite in Figure 3-a). The spectra of phosphates adsorbed onto oxy-hydroxides such as goethite was distinguished from these two species with the presence of an additional oscillation around $2170 \mathrm{eV}^{17}$.

\section{Phosphorous XANES spectra of SS and sludge}

The spectra collected on SS and sludge pellets were found to be very similar to each other (Figure 3-b). The concomitant presence of a pre-edge and a broadening of the white line around 2155.6 $\mathrm{eV}$ attested to the contribution of (i) phosphates- $\mathrm{Fe}^{\mathrm{III}}$ bonds (in the form of either structural $\mathrm{Fe}^{\mathrm{III}}$ in a phosphate mineral or phosphate adsorbed on iron oxide) and (ii) phosphates-calcium bonds (in the form of apatite minerals or phosphates adsorbed onto calcite). Spectra collected with the $\mu$-beam on Prich POIs, selected from $\mu$-XRF maps (not shown), confirmed the presence of $\mathrm{Fe}^{\mathrm{III}}$-species ( $\mathrm{p}$, Figure 3-b). The other types of spectra showed a slight shoulder after the white line and oscillation around $2163 \mathrm{eV}$ (p2 and p3, Figure 3-b) or no shoulder nor oscillation but a broadening of the white line in comparison to organic species ( $\mathrm{p} 4$ and $\mathrm{p} 5$, Figure 3-b). These spectra were close in shape to $\mathrm{ACP}$ but the shoulder and oscillations were less pronounced. Comparison with literature reference spectra showed that spectra $\mathrm{p} 2$ to $\mathrm{p} 5$ were close to phosphate adsorbed onto calcite ${ }^{17}$ or to dicalcium phosphate ${ }^{53,54,56}$. The oscillation around $2163.2 \mathrm{eV}$ remained however less pronounced in the spectra collected on SS and sludge samples than in reference spectra. Additional characterization at Ca K-edge could be useful to clear this uncertainty. Among the collected $\mu$-XANES spectra, none could be attributed to organic $\mathrm{P}$ forms, considering our references and the literature spectra ${ }^{17,57}$. Should organic $\mathrm{P}$ be present in the samples, it was not concentrated in hot spots, but rather dispersed in the matrix of the samples. 
The discrimination between $\mathrm{FePO}_{4}$ and phosphates adsorbed onto ferrihydrite, remained difficult from spectra collected at P K-edge on POIs. However, their corresponding XANES spectra at Fe Kedge evidenced distinct features (Figure 4-a black and gray bold lines, respectively), with an additional peak at $7137.6 \mathrm{eV}$ for $\mathrm{FePO}_{4}$ in comparison to phosphates adsorbed onto ferrihydrite, and an additional peak at $7147.3 \mathrm{eV}$ for ferrihydrite in comparison with $\mathrm{FePO}_{4}$. Comparison with ferrihydrite XANES spectra from literature ${ }^{58}$ showed that the adsorption of phosphates on ferrihydrite did not significantly modify the shape of the XANES spectra, in comparison to pure ferrihydrite.

[Figure 4] a) Iron K-edge XANES spectra of $\mathrm{FePO}_{4}$ (bold black line) and ferrihydrite with sorbed phosphates (bold gray line) compared with $\mu$-XANES spectra collected on POIs of sludge sample (dotted lines). The location of the POIs is indicated on the XRF map in SI figure A. b) $\mu$ XRF spectra of two POIs (black and gray XRF spectra were collected on POIs of one of the black and gray $\mu$-XANES from a), respectively.

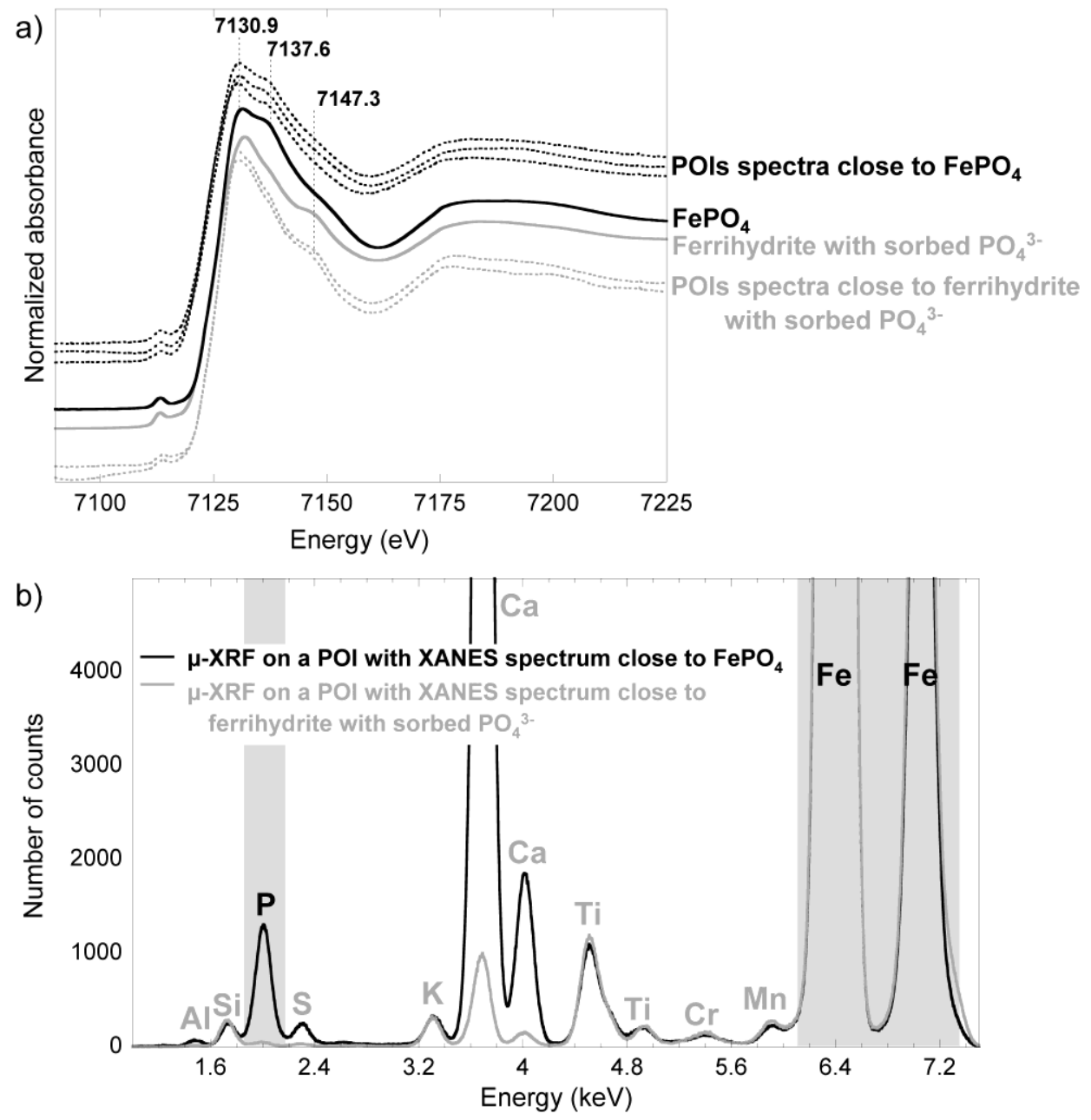


Micro $(\mu)$ XANES spectra collected at Fe K-edge on sludge samples can be split into two sets as a function of their shape. The first set of spectra, (black, Figure 4-a) was close to $\mathrm{FePO}_{4}$ spectrum and the second one (gray, Figure 4-a) close to ferrihydrite. The POIs with spectrum close to $\mathrm{FePO}_{4}$ appeared as the most abundant Fe-bearing species in the sample; XRF maps (SI figure A) systematically evidenced a correlation between Fe and $\mathrm{P}$ in these POIs and the XRF spectrum (black, Figure 4-b) showed a significant contribution of $\mathrm{P}$ in the XRF signal. The POIs close to ferrihydrite were found in marginal amounts. XRF maps (SI figure A) did not show significant correlation between Fe and P, and the XRF spectrum evidenced a negligible amount of $\mathrm{P}$ (gray, Figure 4-b) in comparison to the first XRF spectrum. An additional type of XANES spectrum was also collected in one of Fe-rich POIs (without $\mathrm{P})$, which was attributed to magnetite $\left(\mathrm{Fe}_{3} \mathrm{O}_{4}\right)$. The bulk spectrum collected from sludge sample was well-fitted by a linear combination of $\mathrm{FePO}_{4}$, ferrihydrite, and $\mathrm{Fe}_{3} \mathrm{O}_{4}$ spectra ${ }^{59}$, (with respective contribution of 52, 30, and $19 \%$, Figure 5), confirming the predominance of $\mathrm{FePO}_{4}$ among the Febearing species.

Figure 5. Iron K-edge XANES spectrum of the sludge (black points) and corresponding LCF (gray line) with ferrihydrite, $\mathrm{FePO}_{4}$ and $\mathrm{Fe}_{3} \mathrm{O}_{4}{ }^{59}$ (dotted lines).

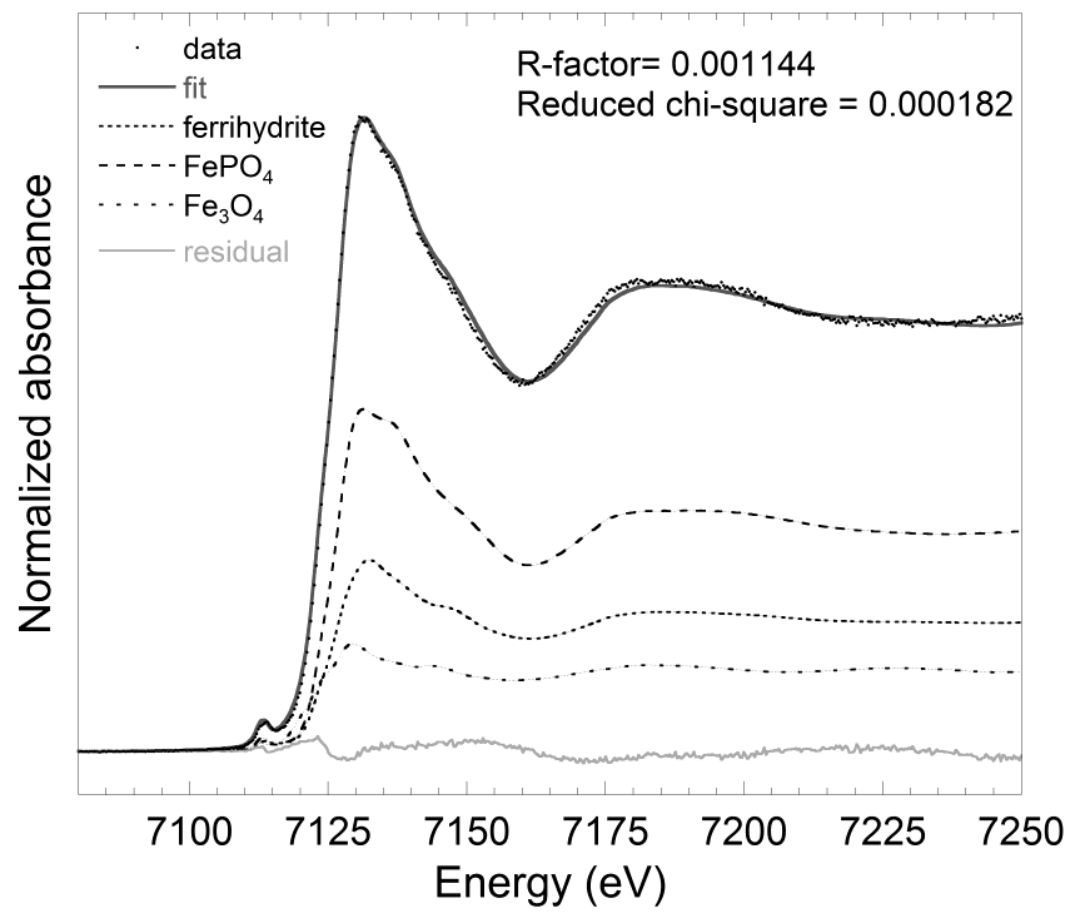


The XANES analyses at Fe K-edge evidenced that $\mathrm{P}$ associated with Fe was mainly in the form of $\mathrm{FePO}_{4}$ minerals. Ferrihydrite was present but in a lower amount and without or with a very low amount of adsorbed phosphate.

\section{Possible effects of aging on phosphorus species}

Analytical results showed that although SS and sludge samples were mostly organic materials, P was mainly present under inorganic forms. Aging phenomena must therefore be considered with respect to both mineral and organic forms of $\mathrm{P}$.

The addition of $\mathrm{FeCl}_{3}$ to flocculate phosphates was found to result predominantly in the formation of ferric phosphate rather than $\mathrm{P}$ species adsorbed onto ferric oxy hydroxide, as shown by XANES analyses.

Under the well-aerated conditions prevailing at the surface of the filters, the most readily biodegradable fraction of organic matter initially present in SS was biodegraded and probably partly mineralized, as shown by the lower organic content in sludge than in SS. The biodegradation process induced a relative increase of $\mathrm{P}$ content in the sludge as compared to $\mathrm{SS}$, with possible consequences on the distribution of P initially bound to the biodegraded matter. XANES analyses revealed the presence of apatitic minerals or phosphates adsorbed onto calcite both in SS and sludge. The fractionation method showed more Ca-bound $\mathrm{P}$ in sludge than in SS, whereas all the other forms of $\mathrm{P}$ were found in smaller proportions in sludge. This set of observations suggested that the partial mineralization of organic matter within the surface deposit layer may have induced the mobilization of the associated P and its combination with calcium present in the wastewater to induce the formation of Ca-bound $\mathrm{P}$ species.

The XRF map collected above Fe K-edge provided also information about calcium (Ca) distribution (SI Figure B). Spatial correlation of Fe, $\mathrm{P}$, and $\mathrm{Ca}$ was observed for some particles, underlining that it could be of interest to pursue the investigations by collection of Ca K-edge XANES.

In parallel to the biodegradation of the most readily biodegradable fraction, the more recalcitrant organic fraction was probably involved in the formation of more complex fulvic and humic structures. These qualitative changes in the structure of organic matter might explain the redistribution of $\mathrm{P}$ revealed by the fractionation method between acid-extractible and alkaline-extractible fractions, and the shift from diesters to monoesters observed by solution ${ }^{31} \mathrm{P}$ NMR. 


\section{SUPPORTING INFORMATION}

Figure A. Iron (Fe, in red)-phosphorous ( $\mathrm{P}$, in green) $\mathrm{X}$-ray fluorescence (XRF) correlation map. Figure B. Iron ( $\mathrm{Fe}$, in red)-phosphorous ( $\mathrm{P}$, in green)-calcium ( $\mathrm{Ca}$, in blue) XRF correlation map showing the presence of three main types of Ca-bearing particles. This material is available free of charge via the Internet at http://pubs.acs.org.

\section{ACKNOWLEDGMENT}

The authors are grateful to SCIRPE and CIFRE (Conventions Industrielles de Formation par la REcherche) for funding this research. They also would like to thank the ID21 beamline staff at the European Synchrotron Radiation Facility for granting in-house beamtime, David Lebouil and Nathalie Dumont of LGCIE for chemical analysis (ICP-AES), and the reviewers for their contribution to the improvement of this manuscript.

The authors declare no competing financial interest.

\section{REFERENCES}

1. Cordell, D.; Drangert, J.-O.; White, S., The story of phosphorus: Global food security and food for thought. Global Environmental Change 2009, 19, (2), 292-305.

2. Cade-Menun, B.; Liu, C. W., Solution Phosphorus-31 Nuclear Magnetic Resonance Spectroscopy of Soils from 2005 to 2013: A Review of Sample Preparation and Experimental Parameters. Soil Science Society of America Journal 2014, 78, (1), 19-37.

3. Stamm, C.; Jarvie, H. P.; Scott, T., What's More Important for Managing Phosphorus: Loads, Concentrations or Both? Environmental Science and Technology 2014, 48, (1), 23-24.

4. Kim, B.; Gautier, M.; Molle, P.; Michel, P.; Gourdon, R., Influence of the water saturation level on phosphorus retention and treatment performances of vertical flow constructed wetland combined with trickling filter and $\mathrm{FeCl3}$ injection. Ecological Engineering 2015, doi.org/10.1016/j.ecoleng.2014.09.097.

5. Kim, B.; Gautier, M.; Prost-Boucle, S.; Molle, P.; Michel, P.; Gourdon, R., Performance evaluation of partially saturated vertical-flow constructed wetland with trickling filter and chemical precipitation for domestic and winery wastewaters treatment. Ecological Engineering 2014, 71, 41-47.

6. Molle, P., French vertical flow constructed wetlands: a need of a better understanding of the role of the deposit layer. Water Science and Technology 2014, 69, (1), 106-112.

7. Kim, B.; Gautier, M.; Michel, P.; Gourdon, R., Physical-chemical characterization of sludge and granular materials from a vertical flow constructed wetland for municipal wastewater treatment. Water Science and Technology 2013, 68, (10), 2257-2263. 
8. Eveborn, D.; Gustafsson, J. P.; Hesterberg, D.; Hillier, S., XANES Speciation of P in Environmental Samples: An Assessment of Filter Media for on-Site Wastewater Treatment. Environmental Science and Technology 2009, 43, (17), 6515-6521.

9. Chang, S. C.; Jackson, M. L., Fractionation of Soil Phosphorus. Soil Science 1957, 84, (2), 133144.

10. Bowman, R. A.; Cole, C. V., An Exploratory Method for Fractionation of Organic Phosphorus From Grassland Soils. Soil Science 1978, 125, (2), 95-101.

11. Hedley, M. J.; Stewart, J. W. B.; Chauhan, B. S., Changes in Inorganic and Organic Soil Phosphorus Fractions Induced by Cultivation Practices and by Laboratory Incubations. Soil Science Society of America Journal 1982, 46, (5), 970-976.

12. Golterman, H., Fractionation of sediment phosphate with chelating compounds: a simplification, and comparison with other methods. Hydrobiologia 1996, 335, (1), 87-95.

13. Maine, M. A.; Suñe, N.; Hadad, H.; Sánchez, G., Temporal and spatial variation of phosphate distribution in the sediment of a free water surface constructed wetland. Science of The Total Environment 2007, 380, (1-3), 75-83.

14. Li, W.; Joshi, S. R.; Hou, G.; Burdige, D. J.; Sparks, D. L.; Jaisi, D. P., Characterizing Phosphorus Speciation of Chesapeake Bay Sediments Using Chemical Extraction, 31P NMR, and Xray Absorption Fine Structure Spectroscopy. Environ Sci Technol 2015, 49, (1), 203-211.

15. Negassa, W.; Kruse, J.; Michalik, D.; Appathurai, N.; Zuin, L.; Leinweber, P., Phosphorus Speciation in Agro-Industrial Byproducts: Sequential Fractionation, Solution 31P NMR, and P K- and L2,3-Edge XANES Spectroscopy. Environmental Science and Technology 2010, 44, (6), 2092-2097.

16. Lehmann, J.; Lan, Z.; Hyland, C.; Sato, S.; Solomon, D.; Ketterings, Q. M., Long-Term Dynamics of Phosphorus Forms and Retention in Manure-Amended Soils. Environmental Science and Technology 2005, 39, (17), 6672-6680.

17. Giguet-Covex, C.; Poulenard, J.; Chalmin, E.; Arnaud, F.; Rivard, C.; Jenny, J. P.; Dorioz, J. M., XANES spectroscopy as a tool to trace phosphorus transformation during soil genesis and mountain ecosystem development from lake sediments. Geochimica et Cosmochimica Acta 2013, 118, 129-147.

18. Kizewski, F.; Liu, Y.-T.; Morris, A.; Hesterberg, D., Spectroscopic approaches for phosphorus speciation in soils and other environmental systems. Journal of Environmental Quality 2011, 40, (3), 751-766.

19. Murphy, J.; Riley, J. P., A modified single solution method for the determination of phosphate in natural waters. Anal Chim Acta 1962, 27, (0), 31-36.

20. Haygarth, P. M.; Sharpley, A. N., Terminology for Phosphorus Transfer. Journal of Environmental Quality 2000, 29, (1), 10-15.

21. De Gregorio, C.; Caravelli, A. H.; Zaritzky, N. E., Performance and biological indicators of a laboratory-scale activated sludge reactor with phosphate simultaneous precipitation as affected by ferric chloride addition. Chemical Engineering Journal 2010, 165, (2), 607-616.

22. Szabó, A.; Takács, I.; Murthy, S.; Daigger, G. T.; Licskó, I.; Smith, S., Significance of Design and Operational Variables in Chemical Phosphorus Removal. Water Environment Research 2008, 80, (5), 407-416.

23. Harouiya, N.; Prost-Boucle, S.; Morlay, C.; Esser, D.; Ruel, S. M.; Molle, P., Performance evaluation of phosphorus removal by apatite in constructed wetlands treating domestic wastewater: column and pilot experiments. International Journal of Environmental Analytical Chemistry 2011, 91 , (7-8), 740-752.

24. Golterman, H. L., The chemistry of phosphate and nitrogen compounds in sediments. Dordrecht: Kluwer Academic Publishers: 2004. 
25. Salomé, M.; Cotte, M.; Baker, R.; Barrett, R.; Benseny-Cases, N.; Berruyer, G.; Bugnazet, D.; Castillo-Michel, H.; Cornu, C.; Fayard, B.; Gagliardini, E.; Hino, R.; Morse, J.; Papillon, E.; Pouyet, E.; Rivard, C.; Solé, V. A.; Susini, J.; Veronesi, G., The ID21 Scanning X-ray Microscope at ESRF. J. Phys.: Conf. Ser. 2013, 425, (18), 182004.

26. Newville, M., EXAFS analysis using FEFF and FEFFIT. Journal of Synchrotron Radiation 2001, 8, (2), 96-100.

27. Ravel, B.; Newville, M., ATHENA, ARTEMIS, HEPHAESTUS: data analysis for X-ray absorption spectroscopy using IFEFFIT. Journal of Synchrotron Radiation 2005, 12, (4), 537-541.

28. Cade-Menun, B. J., Characterizing phosphorus in environmental and agricultural samples by 31P nuclear magnetic resonance spectroscopy. Talanta 2005, 66, (2), 359-371.

29. Newman, R. H.; Tate, K. R., Soil phosphorus characterisation by 31p nuclear magnetic resonance. Communications in Soil Science and Plant Analysis 1980, 11, (9), 835-842.

30. Makarov, M.; Haumaier, L.; Zech, W., The nature and origins of diester phosphates in soils: a 31P-NMR study. Biol Fertil Soils 2002, 35, (2), 136-146.

31. Turner, B. L.; Mahieu, N.; Condron, L. M., The phosphorus composition of temperate pasture soils determined by $\mathrm{NaOH}-\mathrm{EDTA}$ extraction and solution 31P NMR spectroscopy. Organic Geochemistry 2003, 34, (8), 1199-1210.

32. Condron, L. M.; Goh, K. M.; Newman, R. H., Nature and distribution of soil phosphorus as revealed by a sequential extraction method followed by $31 \mathrm{P}$ nuclear magnetic resonance analysis. Journal of Soil Science 1985, 36, (2), 199-207.

33. Dai, K. H.; David, M. B.; Vance, G. F.; Krzyszowska, A. J., Characterization of phosphorus in a spruce-fir spodosol by phosphorus-31 nuclear magnetic resonance spectroscopy. Soil Science Society of America Journal 1996, 60, (6), 1943-1950.

34. Kulaev, I. S.; Vagabov, V. M., Polyphosphate metabolism in micro-organisms. Adv. Microb. Physiol. 1983, 24, 83-171.

35. McDowell, R. W.; Condron, L. M.; Stewart, I.; Cave, V., Chemical Nature and Diversity of Phosphorus in New Zealand Pasture Soils Using 31P Nuclear Magnetic Resonance Spectroscopy and Sequential Fractionation. Nutr Cycl Agroecosyst 2005, 72, (3), 241-254.

36. Tate, K. R.; Newman, R. H., Phosphorus fractions of a climosequence of soils in New zealand tussock grassland. Soil Biology and Biochemistry 1982, 14, (3), 191-196.

37. Stewart, J. W. B.; Tiessen, H., Dynamics of soil organic phosphorus. Biogeochemistry 1987, 4, (1), 41-60.

38. Tate, K. R., The biological transformation of P in soil. Plant Soil 1984, 76, (1-3), 245-256.

39. McDowell, R. W.; Stewart, I., The phosphorus composition of contrasting soils in pastoral, native and forest management in Otago, New Zealand: Sequential extraction and 31P NMR. Geoderma 2006, 130, (1-2), 176-189.

40. Ajiboye, B.; Akinremi, O. O.; Hu, Y.; Jürgensen, A., XANES Speciation of Phosphorus in Organically Amended and Fertilized Vertisol and Mollisol. Soil Science Society of America Journal 2008, 72, (5), 1256-1262.

41. Beauchemin, S.; Hesterberg, D.; Chou, J.; Beauchemin, M.; Simard, R. R.; Sayers, D. E., Speciation of phosphorus in phosphorus-enriched agricultural soils using X-ray absorption near-edge structure spectroscopy and chemical fractionation. Journal of Environmental Quality 2003, 32, (5), 1809-1819.

42. Franke, R.; Hormes, J., The P K-near edge absorption spectra of phosphates. Physica B: Condensed Matter 1995, 216, (1-2), 85-95. 
43. Hashimoto, Y.; Watanabe, Y., Combined applications of chemical fractionation, solution 31PNMR and P K-edge XANES to determine phosphorus speciation in soils formed on serpentine landscapes. Geoderma 2014, 230-231, 143-150.

44. Hesterberg, D., Chapter 11 - Macroscale Chemical Properties and X-Ray Absorption Spectroscopy of Soil Phosphorus. Developments in Soil Science 2010, 34, 313-356.

45. Ingall, E. D.; Brandes, J. A.; Diaz, J. M.; de Jonge, M. D.; Paterson, D.; McNulty, I.; Elliott, W. C.; Northrup, P., Phosphorus K -edge XANES spectroscopy of mineral standards. Journal of Synchrotron Radiation 2010, 18, (2), 189-197.

46. Kar, G.; Peak, D.; Schoenau, J. J., Spatial Distribution and Chemical Speciation of Soil Phosphorus in a Band Application. Soil Science Society of America Journal 2012, 76, (6), 2297-2306.

47. Kruse, J.; Leinweber, P., Phosphorus in sequentially extracted fen peat soils: A K-edge X-ray absorption near-edge structure (XANES) spectroscopy study. Journal of Plant Nutrition and Soil Science 2008, 171, (4), 613-620.

48. $\quad$ Noack, S. R.; Smernik, R. J.; McBeath, T. M.; Armstrong, R. D.; McLaughlin, M. J., Assessing crop residue phosphorus speciation using chemical fractionation and solution 31P nuclear magnetic resonance spectroscopy. Talanta 2014, 126, 122-129.

49. Peak, D.; Kar, G.; Hundal, L.; Schoenau, J., Kinetics and Mechanisms of Phosphorus Release in a Soil Amended With Biosolids or Inorganic Fertilizer. Soil Science 2012, 177, (3), 183-187.

50. Sato, S.; Solomon, D.; Hyland, C.; Ketterings, Q. M.; Lehmann, J., Phosphorus Speciation in Manure and Manure-Amended Soils Using XANES Spectroscopy. Environmental Science and Technology 2005, 39, (19), 7485-7491.

51. Shober, A. L.; Hesterberg, D. L.; Sims, J. T.; Gardner, S., Characterization of phosphorus species in biosolids and manures using XANES spectroscopy. Journal of Environmental Quality 2006, 35, (6), 1983-1993.

52. Toor, G. S.; Hunger, S.; Peak, J. D.; Sims, J. T.; Sparks, D. L., Advances in the characterization of phosphorus in organic wastes: environmental and agronomic applications. Advances in Agronomy 2006, 89, 1-72.

53. Güngör, K.; Jürgensen, A.; Karthikeyan, K., Determination of phosphorus speciation in dairy manure using XRD and XANES spectroscopy. Journal of Environment Quality 2007, 36, (6), 1856-63.

54. Rajendran, J.; Gialanella, S.; Aswath, P. B., XANES analysis of dried and calcined bones. Materials Science and Engineering: C 2013, 33, (7), 3968-3979.

55. Khare, N.; Martin, J. D.; Hesterberg, D., Phosphate bonding configuration on ferrihydrite based on molecular orbital calculations and XANES fingerprinting. Geochimica et Cosmochimica Acta 2007, $71,(18), 4405-4415$.

56. Liu, J.; Yang, J.; Liang, X.; Zhao, Y.; Cade-Menun, B. J.; Hu, Y., Molecular Speciation of Phosphorus Present in Readily Dispersible Colloids from Agricultural Soils. Soil Science Society of America Journal 2014, (1), 47-53.

57. Brandes, J. A.; Ingall, E.; Paterson, D., Characterization of minerals and organic phosphorus species in marine sediments using soft X-ray fluorescence spectromicroscopy. Marine Chemistry 2007, 103, (3-4), 250-265.

58. Manceau, A.; Gates, W. P., Surface structural model for ferrihydrite. Clays and Clay Minerals 1997, 45, (3), 448-460.

59. Rivard, C.; Montargès-Pelletier, E.; Vantelon, D.; Pelletier, M.; Karunakaran, C.; Michot, L. J.; Villieras, F.; Michau, N., Combination of multi-scale and multi-edge X-ray spectroscopy for investigating the products obtained from the interaction between kaolinite and metallic iron in anoxic conditions at $90^{\circ} \mathrm{C}$. Phys Chem Minerals 2013, 40, (2), 115-132. 